\title{
Effect Titanium Dioxide / Paraloid B.72 Nanocomposite Coating on Protection of Treated Cu-Zn Archaeological Alloys
}

\author{
Abeer Gharib ${ }^{1, *}$, Manal Ahmed Maher ${ }^{2,3}$, Sameh Hamed Ismail ${ }^{2}$, Gehad Genidy Mohamed ${ }^{2,4}$ \\ ${ }^{1}$ Conservation department, Faculty of Fine Arts, Minia University, Minia, Egypt \\ ${ }^{2}$ Egypt Nanotechnology Centre, Cairo University, Giza, Egypt \\ ${ }^{3}$ Computed Tomography X-ray Unit, Egyptian Museum, Cairo, Egypt \\ ${ }^{4}$ Chemistry Department, Faculty of Science, Cairo University, Giza, Egypt
}

Email address:

abeer.ibrahim@mu.edu.eg (A. Gharib), Manal.a.maher@gmail.com (M. A. Maher), Drsameheltayer@yahoo.com (S. H. Ismail), ggenidymohamed@sci.cu.edu.eg (G. G. Mohamed)

${ }^{*}$ Corresponding author

\section{To cite this article:}

Abeer Gharib, Manal Ahmed Maher, Sameh Hamed Ismail, Gehad Genidy Mohamed. Effect Titanium Dioxide / Paraloid B.72

Nanocomposite Coating on Protection of Treated Cu-Zn Archaeological Alloys. International Journal of Archaeology.

Vol. 7, No. 2, 2019, pp. 47-54. doi: 10.11648/j.ija.20190702.13

Received: October 19, 2019; Accepted: November 14, 2019; Published: November 25, 2019

\begin{abstract}
Copper alloy samples are subjected to climate chamber test to simulate corrosion compounds of copper artifacts in atmospheric environment. Relative humidity and air pollution considered as an essential source of deterioration and corrosion of archaeological objects. Corroded copper coupons were investigated by X-ray diffraction analysis (XRD) and scanning electron microscopy with energy dispersive X-ray analysis (SEM-EDX) to identify elemental composition of coupon samples and the corrosion products. Mechanical cleaning was used in order to clean the copper coupon surface and carried out nanocomposite coating on treated copper surface. To evaluate performance of titanium dioxide $\mathrm{TiO}_{2} /$ Paraloid B.72 nanocomposite, the nanocomposite coating applied as a thin film at different times $(10,15,30$ minutes). The electrochemical impedance spectroscopy (EIS) of nanocomposite coating layers on treated copper coupons showed different results; that the best layer was obtained from the coupon which immersed in nanocomposite coating for $15 \mathrm{~min}$. To prove successes of $\mathrm{TiO}_{2} /$ Paraloid B.72 nanocomposite as a good protection coating applied on treated copper objects. Nanocomposite coating of $\mathrm{TiO}_{2} /$ Paraloid B.72 were examined under X-ray diffraction analysis (XRD), Raman Spectroscopy, Atomic Force Microscopy (AFM), and Contact angle, which revealed control the wettability and $\mathrm{TiO}_{2} /$ Paraloid $\mathrm{B} .72$ nanocomposite is completely covers and protects the copper substrate without any degradation.
\end{abstract}

Keywords: Nanocomposite Coating, SEM-EDX, XRD, AFM, Contact Angle, Raman Spectroscopy

\section{Introduction}

Corroded archaeological metallic artifacts usually developed from the interactions between metals and their recent or past environment [1]. The most influential factors of deterioration of historical metal objects should be indicated as the relative humidity and air pollution while deterioration of metal object increased in humidity, contaments and amount of gasses in the environment $[2,3]$.

Corrosion of copper and its inhibition are in a wide variety of media, particularly when copper object includes chloride ions. Copper corrosion arises when electrons are lost by the base metal, and the solid phase is changed into soluble, dissolved cuprous $\left(\mathrm{Cu}^{+}\right)$or cupric $\left(\mathrm{Cu}^{2+}\right)$ ions. Chemical oxidation happens at anodes where electrons are released. Alternately, chemical reduction (the gain of the electrons) arises at the cathode [4].

The protection of copper artifacts of the cultural heritage against further corrosion degradation is a key issue. A way to reach that goal is to keep the artifacts in suitable environment with low $\mathrm{RH}$, free of pollutants and of aggressive gases. 
Nevertheless, this is not always possible, due to economic or practical considerations. For that reason, another solution would be to use a protective coating on the artifacts to isolate it from the environment [5], so it is very important to improve corrosion inhibitors to prevent metal dissolution and minimize acid consumption. The good inhibitor has many advantages such as high inhibition efficiency, low price, low toxicity and easy production [6,7]. Nano composite offer such advantages with addition of improvement of the environmental impact.

In the last two decades, nanotechnology has been acting an increasing important role in supporting innovative technological advances to control the corrosion of metal [6]. There are various reports concerning developing corrosion resistance using nanoparticles such as; $\mathrm{TiO}_{2}, \mathrm{Cu}_{2} \mathrm{O}$ [3], $\mathrm{ZnO}$, $\mathrm{ZrO}_{2}$ nanoparticles, $\mathrm{Fe}_{3} \mathrm{O}_{4}$ [6-8], $\mathrm{SiO}_{2}$, and $\mathrm{Au}$ nanoparticles [9-11].

Nanomaterial is used to obtain higher opacity, better interaction between coating and surface and higher durability of the coating. Due to their small particle size of $100 \mathrm{~nm}$ or less, some nanomaterial is appropriate for use in transparent coating systems. This work aims to protect treated copper coupons with Nano composite coating Paraloid B72 and $\mathrm{TiO}_{2}$.

Paraloid B-72 is stable and non-yellowing acrylic resin chemically is a copolymer of ethyl methacrylate and methyl acrylate with a molar ratio of approximately $70-30 \%$. It can be applied for metal conservation [12]. It has been applied extensively in conservation as a surface coating. B-72 gives excellent mechanical properties and hardness without the brittleness and other disadvantages of higher molecular weight resins $[13,14]$. Paraloid B-72 is very stable against water, alkalis, acids, oils and chemical fumes. The layers are very elastic and adhere on metals [15]. B72 soluble in Acetone, Amyl Acetate, n-Butanol, Cellosolve, Diacetone Alcohol, Dimethyl Formamide, Ethyl Alcohol, Ethylene Dichloride, Isopropanol, Methylene Chloride, Methyl Ethyl Ketone, Toluene, Trichloroethane and Xylene. B72 is insoluble in White Spirit $[12,16]$. The alcohol dispersions may be milky. However, they make clear, coherent films [15, 17].

Acrylic polymers affected by degradation through the activities of microbiological organisms. The biodegradation appeared when it used for a long-term protection of archaeological collections and outdoor monuments [18-20].

Nano- $\mathrm{TiO}_{2}$ particles have developed the corrosion resistance of metal. $\mathrm{TiO}_{2}$ nanoparticle coating has been used to avoid biofilm formation in high relative humidity. Recent applications of titanium dioxide $\left(\mathrm{TiO}_{2}\right)$ based on the photocatalysis and photoactivity of $\mathrm{TiO}_{2}$, involve antifouling, antibacterial, and deodorizing [21].

\subsection{The Copper Coupons Preparation}

The copper coupons were cut into four samples with dimensions $5 \times 5 \mathrm{~cm}$. The corrosive Medias carried out by climate chamber designed according to ASTM D5116-97. A small chamber is manufacturing by dimensions
(30x30x30CM) The air inside the chamber is continuously mixed by a fan, the temperature and relative humidity inside the chamber are continuously measured. Gases used for the test were Sulfur dioxide $\mathrm{SO}_{2}$ and chlorine $\mathrm{Cl}$. Those types were the most effective and commonly in deterioration of copper artifacts [22]. The coupons were investigated by Scanning Electron Microscopy and X- ray diffraction analysis. The surface cleaning has been performed by mechanical cleaning. The corroded surface was friction by different glass bristle brushes, careful use scalpels and dental, and then it washed with distilled water then dried with ethyl alcohol.

\subsection{Synthesis of $\mathrm{TiO}_{2} /$ Paraloid B.72 Nanocomposite Thin Film}

Solution of 4\% paraloid B-72 in Isopropanol was prepared, and then $0.5 \mathrm{gm}$ of $\mathrm{TiO}_{2}$ Nano particles was added. The Nano composite coating was carried out in ultra-sonic waves under condition of $90 \%$ amplitude and 0.9 cycles with constant stirring for 2 hours at room temperature. 3 samples were treated with the Nano composite coating to form thin film at $(10,15,30$ minutes) and dried under atmospheric air, so there were four copper coupons, uncoated copper coupon code no.(1), coated copper coupon for $10 \mathrm{~min}$ code no. (2), coated copper coupon for $15 \mathrm{~min}$ code no. (3), and coated copper coupon for 30 min code no. (4).

$\mathrm{TiO}_{2} /$ Paraloid B.72 nanocomposite thin film coated the treated copper coupons were characteristic by XRD, Raman, AFM and Contact angle. XRD and Raman illustrated the composition of $\mathrm{TiO}_{2}$ / Paraloid B.72 nanocomposite thin film coated the treated copper coupons and the corrosion phase. AFM characteristic the presence of valleys, streams and pore due to corrosion process on surface of copper coupons and observation how "Nano-power" treatment the surface and enhancement its corrosion resistance. AFM data also give information about roughens profile, skewness and kurtosis of $\mathrm{TiO}_{2} /$ Paraloid B.72 nanocomposite thin film coated the copper coupons which indicated the quality of thin film and treatment. Figure 1.

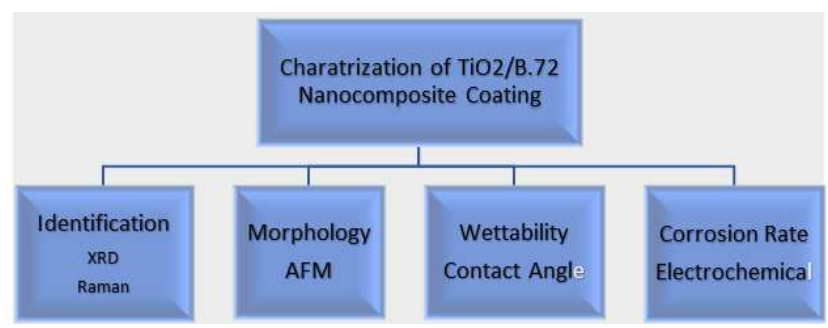

Figure 1. characterization of $\mathrm{TiO}_{2} /$ Paraloid B.72 nanocomposite thin film coated the copper coupons.

\section{Materials and Methods}

To identify the copper alloy and corrosion phases, the coupon was analyzed by scanning electron microscopy with energy dispersive X-ray analysis (SEM-EDX) model (JEOL JEM-100CX 11) to determine elemental composition of 
samples. To identify the corrosion products, the coupons were examined by X-ray powder diffraction (XRD) model (JEOL), under the following conditions: operating voltage: $\mathrm{U}=35 \mathrm{kV}$, current $\mathrm{I}=30 \mathrm{~mA}, \mathrm{X}$-rays from a copper cathode $(\mathrm{Cu})$, wavelength $\mathrm{Cu} \mathrm{K} \alpha=1.5418 \AA, 4-100^{\circ} 2 \theta$, step: $0.1^{\circ}$, Speed: $2 / \mathrm{min}$.

XRD carried out by Bruker D8 DISCOVER Diffractometer with $\mathrm{Cu}-\mathrm{K} \alpha$ radiation $(\lambda=1.54060$ Angstrom $)$ to study the copper coupons which coated with $\mathrm{TiO}_{2}$ and Paraloid B-72 nanocomposite. The relative intensity data were collected over a $2 \theta$ range of $5^{\circ}-100^{\circ}, 2 \theta$ values and relative intensities (I/Io) were determined from the chart, the minerals of core materials were identified with JCPDS carts.

Raman spectroscopy was performed by using a LabRAM HR Evolution Raman spectrometer (HORIBA Jobin Yvon Technology, France) with objective lens 50X. The spectra were recorded at least $15 \mathrm{~s}$ accumulation time with delay time $1 \mathrm{~s}$, in wavelength region 100 and $3199 \mathrm{~cm}^{-1}$ and ND filter laser intensity $25 \%$.

$\mathrm{TiO}_{2}$, B.72 nanocomposite thin film coated the treated copper coupons were characteristic by AFM and Contact angle, XRD and Raman spectroscopy. Morphology, surface topography, roughens profile, skewness and kurtosis have been done using AFM instrument model 5600Ls manufacture by Agilent Technology Company (USA). Experimental condition was contact mode, gold tap, I Gain 0.5, P Gain and speed $1 \mathrm{inch} / \mathrm{sec}$. The size of AFM Images was $25 \mathrm{X} 25 \mu \mathrm{m}$ and $5 \times 5 \mu \mathrm{m}$ (Zoom from $25 \times 25 \mu \mathrm{m}$ AFM image). Using Pico image basics software version 6.2 coupons measure its contact angle by contact angle analyzer model T200 manufacture by Biolin Scientific under condition of sessile drop recipe, droplet distilled water volume $4 \mu \mathrm{m}$ and measure time $10 \mathrm{sec}$. measure mean contact angles are 88.91, 147.69, 156.16 and $165.36^{\circ}$ for the coupons, respectively.

Electrochemical impedance spectroscopy (EIS) measurements carried out including potentiodynamic polarization. The corrosion resistance of coated copper coupons investigated via potentiodynamic polarization curves acquired by EIS in $3.5 \mathrm{wt} \%$ sodium chloride $(\mathrm{NaCl})$ solution in water. Open circuit potential (OCP) and polarization time studies for all coupons were $30 \mathrm{~min}$. Electrochemical experiments were performed using AUTOLAB, equipped with a standard three-electrode system with an $[\mathrm{Ag} / \mathrm{AgCl}]$ reference electrode, a platinum mesh as the counter electrode, and the sample as working electrode. The Tafel curves were used to determine the corrosion resistance of each coupons.

\section{Results and Discussion}

\subsection{Identification of Corrosion Products on Copper Coupons by (XRD)}

To identify the corrosion products, the coupons were examined by X-ray powder diffraction (XRD). Figure 2 shows the presence of nantokite $\mathrm{CuCl}$, atacamite $\mathrm{Cu}_{2}(\mathrm{OH})_{3} \mathrm{Cl}$, paratacamite $\mathrm{Cu}_{2}(\mathrm{OH})_{3} \mathrm{Cl}$ and chalcocite $\mathrm{Cu}_{2} \mathrm{~S}$.
It can be suggested that the green phase is a mixture of copper trihydroxychlorides (atacamite, paratacamite), and the greyish-white phase concentrated in the core of the objects may be nantokite.

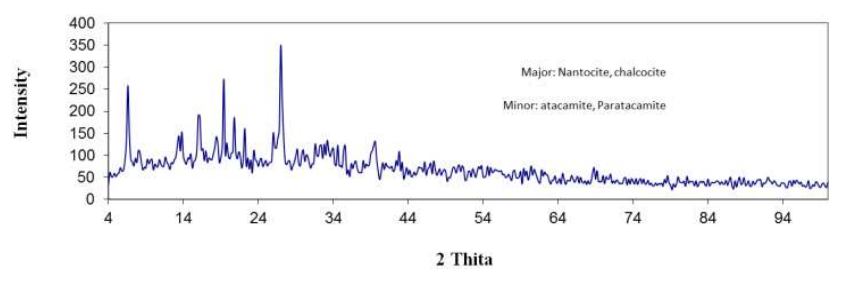

Figure 2. Shows XRD pattern of corroded copper coupon samples which consists of nantokite, chalcocite, atacamite, and paratacamite.

\subsection{Elemental Analysis of Corroded Copper Coupons by (SEM-EDX)}

SEM micrograph of the alloy Figure 3 showed the alloy structure with different size of corrosion crystals. EDX analysis Figure 4 showed the alloy is Brass alloy (copper and zinc) with different contamination elements $(\mathrm{S}, \mathrm{O}, \mathrm{Na}, \mathrm{Cl})$ coming from the surrounding environment.


Figure 3. Shows the SEM micrograph of the alloy.

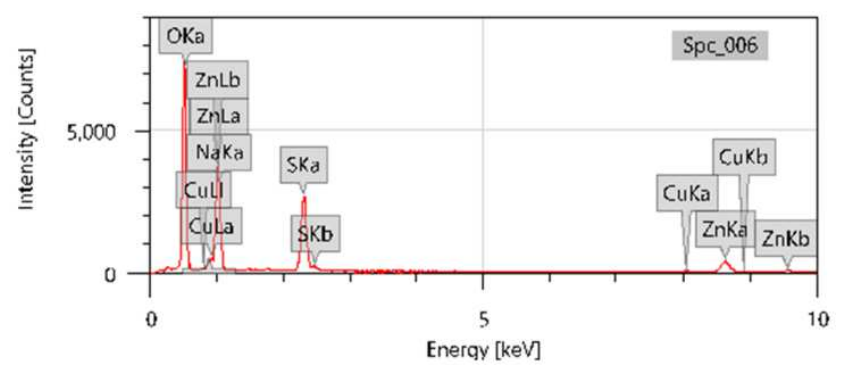

Figure 4. Reveals the EDX analysis of the alloy.

\subsection{Analytical Composition of $\mathrm{TiO}_{2} /$ Paraloid B. 72 Nanocomposite Thin Film by XRD}

Figure 5 illustrated XRD patterns of deep coating layer of $\mathrm{TiO}_{2}$ / Paraloid B.72 nanocomposite on copper substrates in different times at 10, 15 and 30 minutes respectively. XRD patterns reveal well developed XRD reflections of $\mathrm{TiO}_{2}$ nanoparticles, copper, Memorable that the Bragg reflections of $\mathrm{TiO}_{2}$ NPs were increased and seen in the XRD patterns by increase the immersion time, it was obviously shown in the figure (10-D). Since, $\mathrm{TiO}_{2} \mathrm{NPs}$ exhibit the characteristic peaks at $2 \theta=27.45^{\circ}, 36.07^{\circ}, 41.24^{\circ}$ and $54.34^{\circ}$ which corresponds to (110), (101), (111) and (211) crystal planes by relative intensities $100 \%, 50 \%, 30 \%, 60 \%$ respectively. Strong Bragg reflections of copper were seen in all XRD patterns which correspond to the reflection of substrate. Copper exhibit the characteristic peak at $2 \theta=43.50^{\circ}, 50.41^{\circ}$, 
$74.06^{\circ}, 90.02^{\circ}, 95.67^{\circ}$ which corresponds to the (111), (200), (220), (311), (222) planes

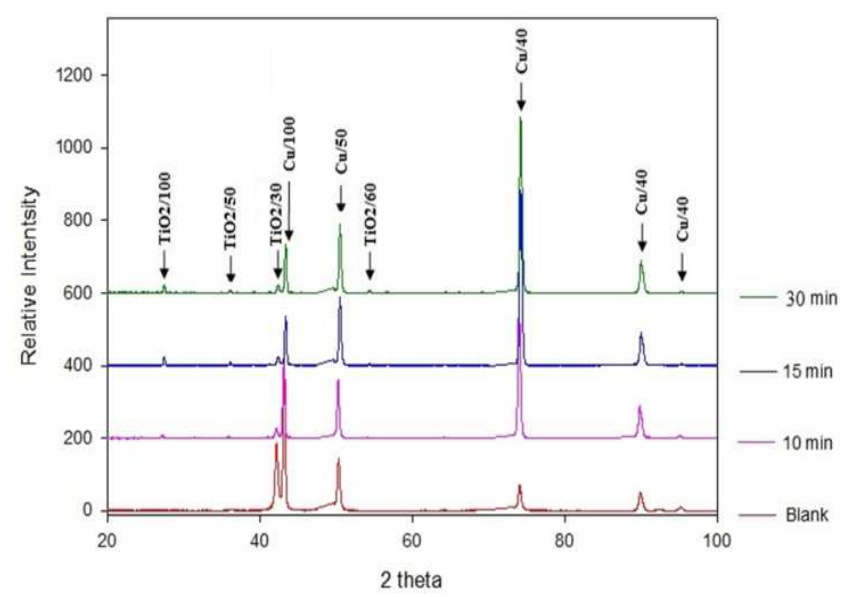

Figure 5. XRD patterns of copper coupons coated with $\mathrm{TiO}_{2}$ and Paraloid B72 nanocomposite.

\subsection{Investigation of $\mathrm{TiO}_{2} /$ Paraloid B.72 Nanocomposite} Thin Film by Raman Spectroscopy

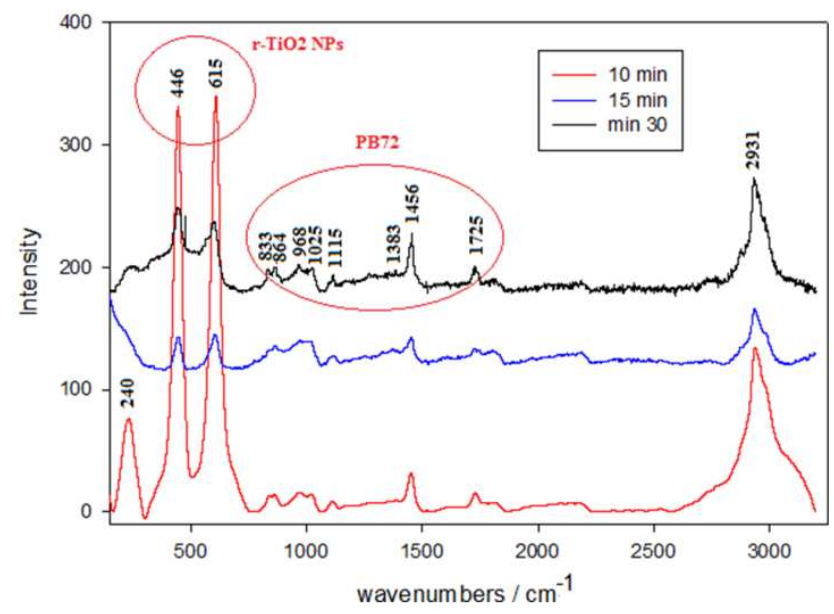

Figure 6. Raman spectrum of copper coupons coated with $\mathrm{TiO} 2$ and Paraloid B-72 nanocomposite.

Figure 6 illustrated XRD patterns of deep coating layer of $\mathrm{TiO}_{2}$ / Paraloid B.72 nanocomposite on copper substrates in different times at 10,15 and 30 minutes respectively. Raman spectra reveal a counterpart of the synthesized $\mathrm{r}-\mathrm{TiO}_{2} \mathrm{NPs}$ at $610 \mathrm{~cm}^{-1}$, and it show an average broaden peaks at wavenumbers 446 and $240 \mathrm{~cm}^{-1}$ respectively. Since, $r-\mathrm{TiO}_{2}$ NPs show a downward dispersion Raman spectrum curve at Eg $\left(446 \mathrm{~cm}^{-1}\right)$ and $\mathrm{A}_{l g}\left(610 \mathrm{~cm}^{-1}\right)$. The spectra of Paraloid B72 (PB72) with their chemical composition, namely evidence is found of the ester group by the mode near 1730 $\mathrm{cm}^{-1}$, and of $\mathrm{CH} 2$ and $\mathrm{CH} 3$ groups near 1440 and $1370 \mathrm{~cm}^{-1}$. The increased complexity of the spectra of PB72 is expected, this is due to it is a random copolymer. The most identify signal of PB72 (at $990 \mathrm{~cm}^{-1}$ ) presence in the broads 968 and $1025 \mathrm{~cm}^{-1}$ which attributed to $\mathrm{CH}$ groups in $\mathrm{CH} 2=\mathrm{CHCOOR}$. Also, PB72 spectra fluorescence effect at $1456 \mathrm{~cm}^{-1}$ (which represent to methylene group bonding), was clearly observed in the present findings. The intensity of the bands attributable to $\mathrm{C}-\mathrm{O}-\mathrm{CH} 3$ or $\mathrm{C}-\mathrm{O}-\mathrm{CH} 2-\mathrm{CH} 3$ was lower, this probably due to its polymerization degree. Memorable that the Raman spectra of copper were not observed in the present spectra, this may be due to most increase of $\mathrm{TiO}_{2} \mathrm{NPs}$ and grow of PB72 which may hide the copper spectra. This confirms that the $\mathrm{r}-\mathrm{TiO} / \mathrm{PB} 72$ nanocomposite is completely covers and protects the copper substrate.

\subsection{Morphological and Structural of $\mathrm{TiO}_{2} /$ Paraloid B. 72 nanocomposite Thin Film Coated the Copper Coupons}

AFM images has been examined not only conformed presence of $\mathrm{TiO}_{2} /$ Paraloid B.72 nanocomposite thin film coated the copper coupons but also study corrosion products (pores, streams and valley) and evaluation the treatment quality. Coupon (1) presents the best corrosion products where valleys, streams and pores are very clear and sharp with size from $1 \mu \mathrm{m}$ to several $\mathrm{mm}$ which revealed the uncoated surface of copper coupon (1). $25 \times 25 \mu \mathrm{m}$ AFM image of coupon (1) as show in Figure 8 (a). illustrate the huge valley about $10 \mu \mathrm{m}$ (reddish orang to red color), symmetry parallel streams have the same size about 1 to $2 \mu \mathrm{m}$ (yellow color) and copper alloy rest on top surface (blue color). surface layer indicates the large area on AFM image (green color) which revealed the highly corrosion stat of uncoated coupon no. (1). Although $25 \times 25 \mu \mathrm{m}$ AFM image of coupon (1) shows copper alloy batch on surface of copper alloy with homogenous particles distribution without any corrosion product but when zoom to $5 \times 5 \mu \mathrm{m}$ reveal pore. Total height of roughness profile (Rt) is $5.5 \mu \mathrm{m} 3.25 \mu \mathrm{m}$ for $25 \times 25 \mu \mathrm{m}$ and $5 \times 5 \mu \mathrm{m}$. However, this high (Rt) showed the difficulty of coated copper coupon by common materials thin film. This difficulty will illustrate the "Nano-power" and how can be helpful on protect the surfaces. Roughness skewness (Rsk) which employed to measure the quality of symmetry of thin film where is more sensitive to valleys or high peaks is 0.0306 which revealed the asymmetry and bad bearing surface of coupon (1) due to corrosion method where the distribution of heights peaks or/and pores, streams and deep valley are not homogenous with valleys more than heights peaks. Roughness kurtosis ( $\mathrm{Rku})$ is employed to measure the planner quality of thin film where is more sensitive to distribution of curves is 2.47 which revealed the curvy surface (mesokurtic) of coupon (1) due to a lot of pores, streams and deep valleys.

$\mathrm{TiO}_{2} /$ Paraloid B.72 nanocomposite thin film coated coupon (2) (10 minutes) AFM $25 \times 25 \mu \mathrm{m}$ image as show in Figure 7 (b) revealed the disappeared of valleys and streams just big pores still occurred due to fill of them by $\mathrm{TiO}_{2}$ nanoparticles (Green and blue color) but still there is part of the surface uncoated (yellow color). AFM $5 \times 5 \mu \mathrm{m}$ image zoom taken from good coating area to conform the presence of mesopores. However, there are no presence to mesopores but there is uncoated surface (green color) which indicated the good coat of $\mathrm{TiO}_{2} /$ Paraloid B.72 nanocomposite thin film on coupon (2).

$\mathrm{TiO}_{2}$ / Paraloid B.72 nanocomposite thin film coated 
coupon (3) (15 minutes) AFM 25X25 $\mu \mathrm{m}$ image as show in Figure 8 (a) illustrated the disappeared of valleys and streams just small pores still found due to over fill of them by $\mathrm{TiO}_{2}$


image shows no presence to mesopores which indicated the very good coat of $\mathrm{TiO}_{2} /$ Paraloid B.72 nanocomposite thin film on coupon (3) on this area.

$\mathrm{TiO}_{2} /$ Paraloid B.72 nanocomposite thin film coated coupon (4) (30 minutes) AFM $25 \times 25 \mu \mathrm{m}$ image as show in Figure 9 (b) illustrated the disappeared of pores, valleys and streams due to over fill of them by $\mathrm{TiO}_{2}$ nanoparticles (Green and blue color) due to coated by $\mathrm{B} 72$ - $\mathrm{TiO} 2$ nanocomposite thin film. AFM $5 \times 5 \mu \mathrm{m}$ zoom image shows no presence to mesopores or corrosion layers with homogenous heights peaks which indicated the best coat of $\mathrm{TiO}_{2} /$ Paraloid B.72 nanocomposite thin film on coupon (4) on this area.

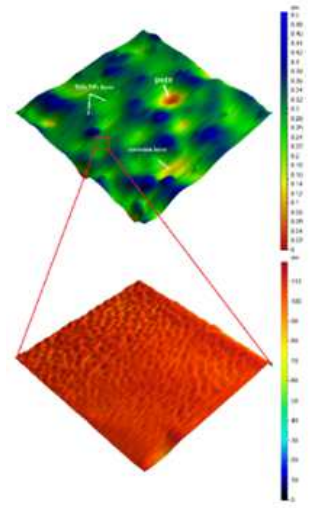

(a)



(b)
Figure 7. (a) AFM $25 X 25 \mu \mathrm{m}$ image and AFM $5 X 5 \mu \mathrm{m}$ zoom image of coupon

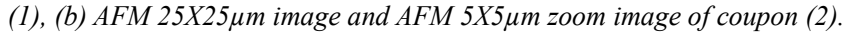

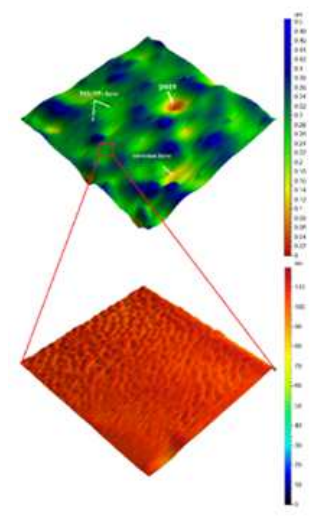

(a)

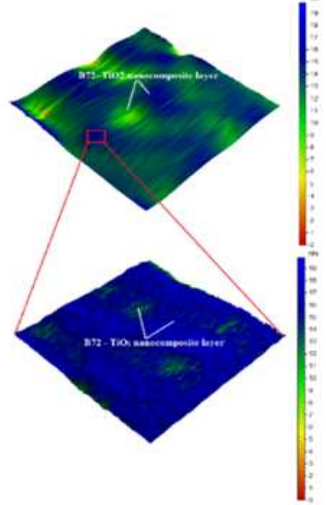

(b)

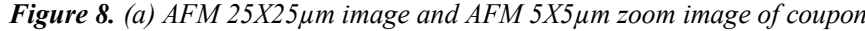

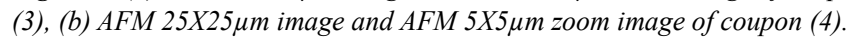

Roughness skewness (Rsk) of $\mathrm{TiO}_{2} /$ Paraloid B.72 nanocomposite thin film on copper alloy sheet (2, 3, and 4) are $-0.623,-0.87$ and -0.942 , respectively. The negative and increased Roughness skewness (Rsk) values indicated the change from asymmetry coupon (1) to symmetry when coated by $\mathrm{B} 72-\mathrm{TiO}_{2}$ nanocomposite thin film and increased this symmetry by increased time soaking cooper coupons on $\mathrm{B} 72-\mathrm{TiO}_{2}$ nanocomposite solution.

Roughness kurtosis (Rku) of $\mathrm{TiO}_{2} /$ Paraloid B.72 nanocomposite thin film on coupons $(2,3$, and 4$)$ are 3.79 , 5.25 and 9.34, respectively. Roughness kurtosis ( $\mathrm{Rku}$ ) values are more than 3 and increased indicated the change from curvy surface (mesokurtic) coupon (1) to plane surface (leptokurtic) when coated by $\mathrm{TiO}_{2} /$ Paraloid B.72 nanocomposite thin film and increased this leptokurtic by increased time soaking copper coupons on $\mathrm{TiO}_{2} /$ Paraloid B.72 nanocomposite solution.

3.6. Wettability of $\mathrm{TiO}_{2}$ / Paraloid B.72 Nanocomposite Thin Film Coated the Treated Copper Coupons

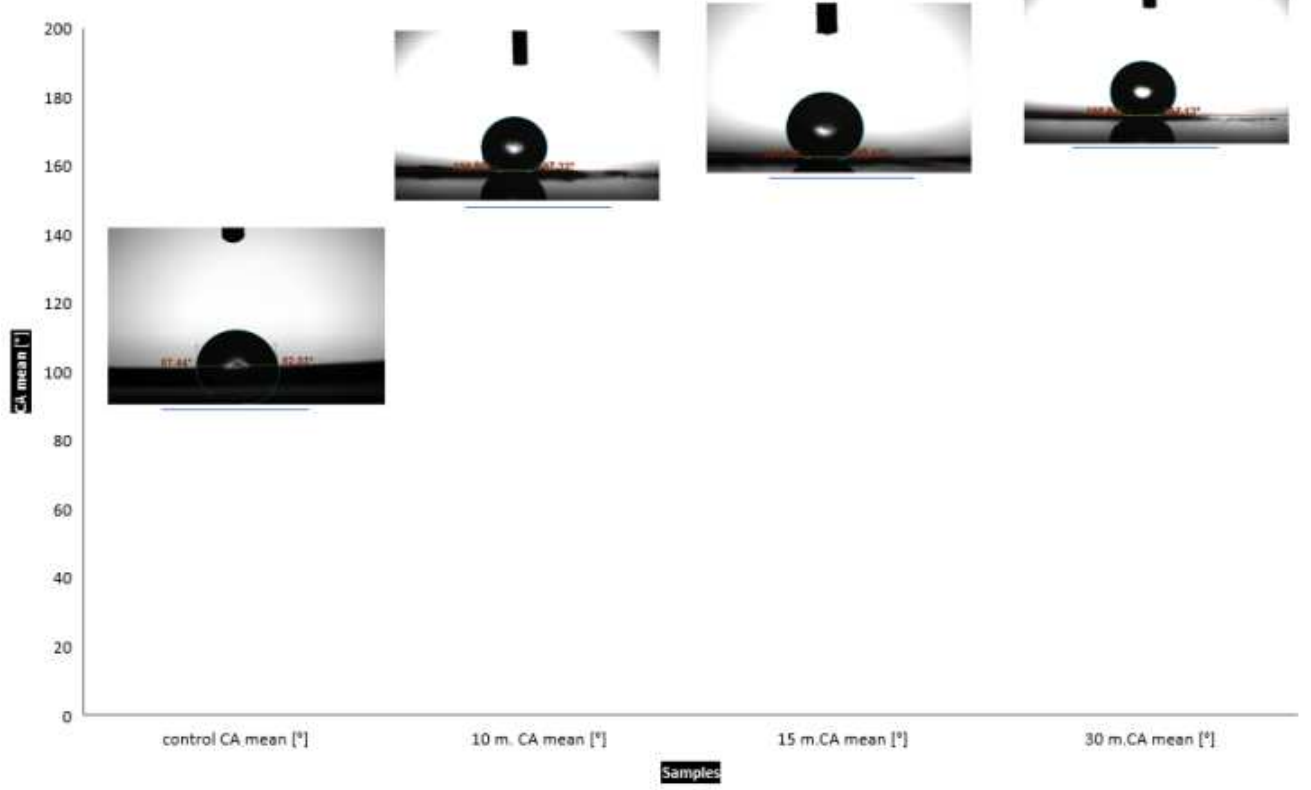

Figure 9. Mean contact angle of all coupons show increase the value towered increase time of soaking. 

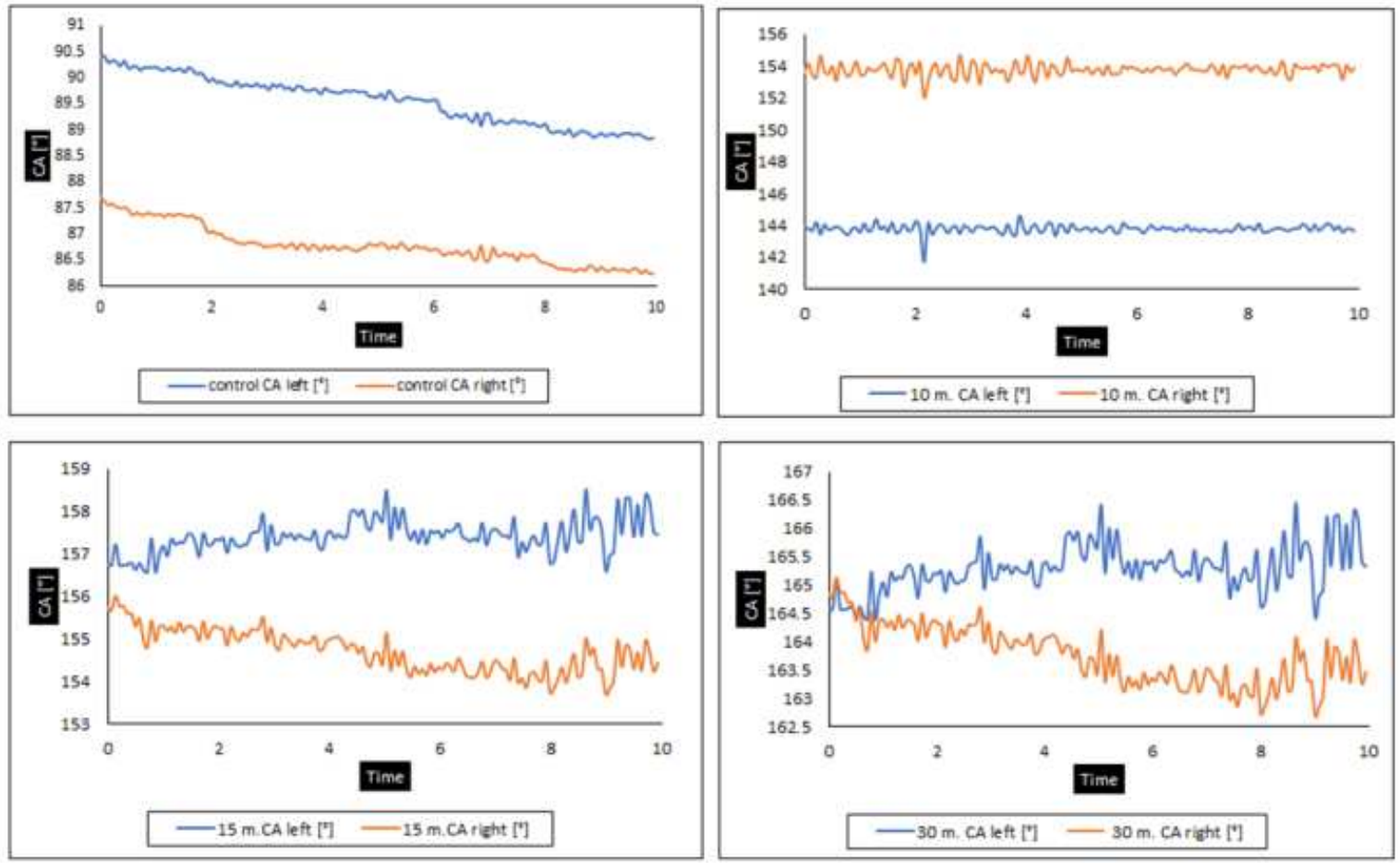

Figure 10. Left and right contact angle of all coupons.

The interaction between copper coupons and water is one of the most important reason for its corrosion state. So $\mathrm{TiO}_{2} /$ Paraloid B.72 nanocomposite thin film on copper coupons (2, 3 , and 4) should be enhanced contact angle value to change the hydrophilic surface to hydrophobic or/and super hydrophobic one. Figure 9 Increase the hydrophobicity by increased time of soaking copper coupon on $\mathrm{TiO}_{2}$ nanocomposite solution explained the mechanism of treatment. However, firstly $\mathrm{TiO}_{2}$ nano particles performance as Nano filler to fill the valleys, streams and pores results of coupon surface and take a time to full filling then thin film coating the surface using $\mathrm{TiO}_{2} /$ Paraloid B.72 nanocomposite which when dry make very high surface tension thin film can protect the copper coupons from water. Coupon 1 have a low contact angle value due to presence a lot of valleys, streams and pores which adsorbed water by capillary and gravity phenomena. While $\mathrm{TiO}_{2} /$ Paraloid B.72 nanocomposite thin film on coupons 2, 3 and 4 have very high contact angle value (super hydrophobic) due to fill the valleys, streams and pores. The increased contact angle toward increased time of soaking because enhancement pore filling by time. Compare left and right contact angle with time of all coupons to show the symmetry of thin film and ability of them to control the wettability. Coupon (1) shows about $4^{\circ}$ difference between left and right contact angle which revealed the asymmetry of it and reduced contact angle with time due to uncontrol wettability. Difference between left and right contact angle coupons 2,3 and 4 are 10,1 and $0.5^{\circ}$ which indicated the asymmetry of coupon (2) and symmetry of coupons (3) and (4) which conformed presence of big pores on coupon 2 and disappeared on coupons (3, and 4) which indicated control the wettability Figure 10.

\subsection{Nano Composite Coating Effectiveness Assessment by EIS}

In order to evaluation the effectiveness of the prepared Nano composite coating and investigate the corrosion inhibitive ability of copper coupons, electrochemical impedance spectroscopy (EIS) measurements carried out. Result of potentiodynamic polarization measurements is shown in Figure 11. Electrochemical parameters with corrosion potential $\left(\mathrm{E}_{\text {corr }}\right)$, corrosion current $\left(\mathrm{i}_{\text {corr }}\right)$ and corrosion rate are usually estimated from polarization curves via Tafel extrapolation method using the attached program of electrochemical workstation and the results are given in table 1.

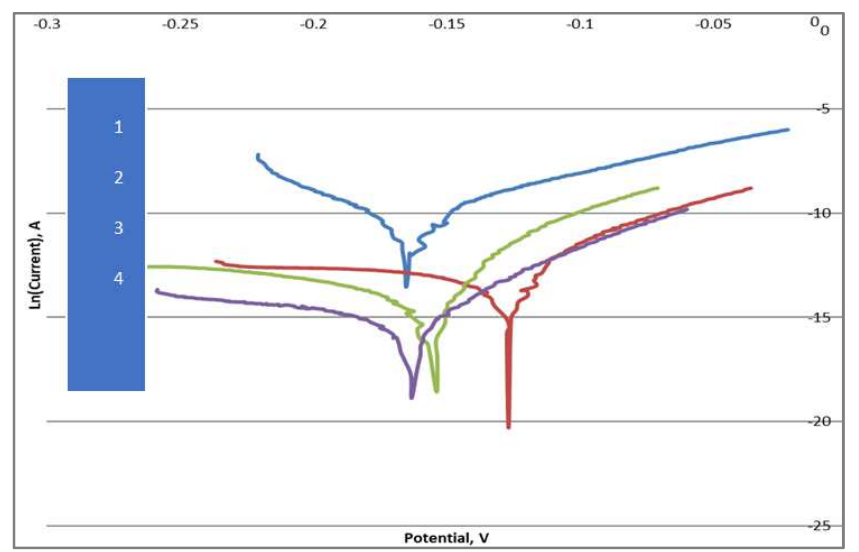

Figure 11. Potentiodynamic curves of (1) uncoated coupon (1), (2) of coupon2, (3) of coupon3, (4) of coupon4. 
Table 1. Tafel extrapolation results obtained from Tafel plots shown in Figure 12.

\begin{tabular}{|c|c|c|c|c|c|c|c|c|}
\hline $\begin{array}{l}\text { Sample } \\
\text { code }\end{array}$ & ba (V/dec) & bc $(\mathrm{V} / \mathrm{dec})$ & $\begin{array}{l}\text { Ecorr, } \\
\text { Calc (V) }\end{array}$ & $\begin{array}{l}\text { Ecorr, Obs } \\
\text { (V) }\end{array}$ & jcorr $\left(A / \mathrm{cm}^{2}\right)$ & icorr (A) & $\begin{array}{l}\text { Corrosion rate } \\
(\mathrm{mm} / \text { year) }\end{array}$ & $\begin{array}{l}\text { E Begin } \\
\text { (V) }\end{array}$ \\
\hline 1 & 0.048502 & 0.049501 & -0.16382 & -0.16492 & 0.000024346 & 0.000024346 & 0.2829 & -0.21011 \\
\hline 2 & 0.096605 & 0.029103 & -0.12905 & -0.12712 & $9.75 \mathrm{E}-07$ & $1.15 \mathrm{E}-06$ & 0.011326 & -0.16235 \\
\hline 3 & 0.1217 & 0.028966 & -0.15597 & -0.15561 & 7.72E-07 & $7.72 \mathrm{E}-07$ & 0.0089692 & -0.21454 \\
\hline 4 & 0.053553 & 0.029587 & -0.16411 & -0.164 & $1 \mathrm{E}-07$ & $1.28 \mathrm{E}-07$ & 0.0011622 & -0.18936 \\
\hline
\end{tabular}

These results revealed the corrosion resistance measurement of coated and uncoated coupons varying. As shown in table 1 the corrosion rate of uncoated coupon (1) is 0.2829 , the corrosion rate of coated coupon for $10 \mathrm{~min}$ in Nano composite coating is 0.0113 , the corrosion rate of coated coupon for $15 \mathrm{~min}$ in Nano composite coating is 0.0089 , the corrosion rate of coated coupon for $30 \mathrm{~min}$ in Nano composite coating is 0.0011 , But it has a cloudy appearance, so the best result was obtained from the coupon which immersed in Nano composite coating for $15 \mathrm{~min}$.

\section{Conclusion}

This study aimed to evaluate the corrosion inhibition performance of $\mathrm{TiO}_{2} /$ Paraloid B.72 Nanocomposite. The nanocomposite coating applied as a thin film on treated copper coupons, the Nano-composition thin film was characteristic by AFM, Contact angle, XRD, and Raman spectroscopy. The characterization of $\mathrm{TiO}_{2} /$ Paraloid B.72 nanocomposite not only to determine quality of chemical and physical properties of the Nano-composition coating, but also to prove successes of $\mathrm{TiO}_{2}$ / Paraloid B.72 nanocomposite as a good protection coating applied on copper objects without any degradation.

XRD analysis and Raman spectroscopy revealed that the nanocomposite coating is completely covers the copper surface and form a protect film on the treated copper surface. The AFM indicated the incorporation of $\mathrm{TiO}_{2}$ Nano-particles in the Paraloid B72 coating improvement corrosion resistance of the Nanocomposite coating as it fills pores and valleys found on copper surface as a result from atmospheric corrosion. The contact angle measurement confirmed the nanocomposite coating did not contact with water on treated copper surface which indicated control the wettability.

EIS data indicated that $\mathrm{TiO}_{2} /$ Paraloid B.72 nanocomposite reduce the corrosion rate on treated copper and exhibit good performance on treated copper coupon immersed on the nanocomposite coating for $15 \mathrm{~min}$ as barrier property against atmospheric corrosion. This excellent corrosion resistance of the Nano- composite coating provide wide applications in protection copper artifacts.

\section{References}

[1] A., Grassini; E., Angelini; Y., Mao; J., Novakovic and P., Vassiliou (2011). Aesthetic Coating for Silver Based Alloy with Improved Protection Efficiency, Progress in Organic Coatings, 72, 131-137.

[2] A. M. Mezzasalma, G. Mondio, T. Serafino, G. De Fulvio, M.
Romeo, A. Salici, (2009). Ancient Coins and their Modern Fakes: An Attempt of Physio-chemical Unmasking, Mediterranean Archaeology and Archaeometry, Vol. 9, No. 2, PP. 15-28.

[3] D. A. Scott, J. Podany, B. B. Considine, Ancient and Historic Metals, Conservation and Scientific Research, The Getty Conservation Institute, 1991.

[4] M., Noroozifar; M., Motlagh; Z, Yavari (2013). Effect of Nano-TiO2 Particles on the Corrosion Behavior of Chromium - Based Coatings, Int. J. Nano Sci. Nano Technol., Vol. 9, No. 2, 85-94.

[5] Ph., Dilmann, Nano Scale Aspects of Corrosion Cultural Heritage Metals, Atlantis Press, https://hal-cea.archivesOuvertes.fr/cea-01338155, 2016, P 233-252.

[6] R. S., Abdel Hameed; H., Abd-Alhakeem, H. A., Shehata (2013). Nano-composite as Corrosion Inhibitors for Steel Alloys in different Corrosive media, Advances Applied Science Research, 4 (3): 126-129.

[7] K. L., Palanisamy, V.; Devabharathi, and M., Sundara (2014). Corrosion Inhibition Studies of Mild Steel with Carrier Oil Stabilized of Iron Oxide Nano Particles Incorporated into A Paint, International Journal of Chem. Tech Research, Vol. 7, No. 4, 1661-1664.

[8] A. M., Atta; G. A., El-Mahdy, and A., Al-lohedan (2013). Corrosion Inhibition Efficiency of Modified Silver Nano Particles for Carbon Steel in 1M HCL, Int. J. Electrochemical Science, 8, 4873-4885.

[9] G. Gao; H. Wu, R. He, D. Cui (2010). Corrosion Inhibition during Synthesis $\mathrm{Cu} 2 \mathrm{O}$ Nano particles by 1, 3 diaminopropylene in Solution, Corrosion Science Journal, 52, 9, 2804-2812.

[10] M., Behzadnasab; S. M., Mirabedini, S., Jamali (2011). Corrosion Performance of Epoxy Coatings Containing Silane Treated $\mathrm{ZrO} 2$ Nano- Particles on Mild Steel in 3. $5 \% \mathrm{NaCl}$ Solution, Corrosion Science, 53, 1, 1-528.

[11] A. M., Atta; O. E., El-Azabawy; H. S., Ismail, M. A., Hegazy (2011). Novel Dispersed Magnetite Core- Shell Nano- gel Polymers as Corrosion Inhibitors for Carbon Steel in Acidic Medium, Corrosion Science, 53, 5, 1627-2050.

[12] J., Leuninger, F., Tiarks, H., Wiese, B., Schuler, Wässrige Nano Komposite. Farbe \& Lack 10/2004 S. 30 http://www. european-coating. com.

[13] S. P., Koob (1986). The Use of Paraloid B-72 as an Adhesive: Its Application for Archaeological Ceramics and Other Materials, Studies in Conservation, 31 (1986) 7-14.

[14] P., Spathis, E., Karagiannidou, A. E., Magoula (2003). Influence of Titanium Dioxide Pigments on the Photo degradation of Paraloid Acrylic Resin, Studies in Conservation, 48, 57-64. 
[15] R. L., Feller (1984). Thermoplastic Polymers Currently in Use as Protective Coatings and Potential Directions for Further Research, ICCM Bulletin, 10, 5-18.

[16] Technical Data Sheet: Paraloid B-72 Preservation Equipment Ltd, https://www. preservationequipment. com.

[17] C. V., Horie, Materials for Conservation: Organic Consolidates, Adhesives and Coatings, Architectural press, Oxford, 1997.

[18] C., Heyn, K., Petersen, W. E., Krumbein, Investigations on the Microbial Degradation of Synthetic Polymers used in the Conservation and Restoration of Art Objects, in Bio deterioration and Biodegradation 9, by A. Bouscher, M. Chandra and R. Edyvean (eds.). Rughy: Institute of chemical Engineers, 1995, PP. 73-79.

[19] P. Spathis, E. Karagiannidou, A. E., Magoula (2003).
Influence of Titanium Dioxide Pigments on the Photodegradation of Paraloid Acrylic Resin, Studies in Conservation, $48-1$.

[20] S. Gagliardi, F. Rondino, C. D’Erme, et al., (2017). preparation and characterization of polymeric Nanocomposite films for application as protective coatings, AIP Conference, 1873-020007.

[21] P., Nithyadevi, R. J., Rathish, J. S., Bama, S., Rajendran, P. M., Joany, A. A., Pandiarajan (2016). Inhibition of Corrosion of Mild Steel in Well Water by $\mathrm{TiO} 2$ Nano particles and an Aqueous Extract of May Flower, Nano Systems: Physics, Chemistry, Mathematics, 7, 4, 711-723.

[22] M., Abd-Elhady, A., Mohammed, Y., Salem, Comparison among the best and widely Compounds used Copper Artefacts Protect Atmospheric Environment, 2016 https://www.researchgate.net. 